\title{
Structure and electrical resistivity of individual carbonised natural and man-made cellulose fibres
}

\author{
Wolfgang Gindl-Altmutter ${ }^{1, \star}$ (1), Ivana Czabany ${ }^{1}$, Christoph Unterweger ${ }^{2}$, Notburga Gierlinger ${ }^{3}$, \\ Nannan $\mathrm{Xiao}^{3}$, Sabine C. Bodner ${ }^{4}$, and Jozef Keckes ${ }^{4}$ \\ ${ }^{1}$ Department of Materials Science and Process Engineering, BOKU-University of Natural Resources and Life Science, Vienna, Konrad \\ Lorenz Strasse 24, 3430 Tulln, Austria \\ ${ }^{2}$ Wood K Plus - Kompetenzzentrum Holz GmbH, Altenbergerstrasse 69, 4040 Linz, Austria \\ ${ }^{3}$ Department of Nanobiotechnology, BOKU-University of Natural Resources and Life Science, Vienna, Muthgasse 11, 1190 Vienna, \\ Austria \\ ${ }^{4}$ Department of Materials Physics, Montanuniversität of Leoben, Jahnstrasse 12, 8700 Leoben, Austria
}

Received: 10 March 2020

Accepted: 25 April 2020

Published online:

7 May 2020

(C) The Author(s) 2020

\begin{abstract}
Carbon fibres were produced from two natural and two man-made cellulose fibres, respectively, in a high-temperature carbonisation process. The structure of the fibres was analysed by means of wide-angle X-ray scattering and Raman spectroscopy. It was found that longitudinal shrinkage of the fibres during carbonisation is correlated with the degree of orientation of cellulose crystals as determined by wide-angle X-ray scattering. Numerous micro-scale defects were found in carbonised natural cellulose fibres, particularly hemp, whereas the structural integrity of carbonised man-made cellulose was better preserved. Both Raman spectroscopy and wide-angle X-ray scattering revealed a trend of diminishing electrical resistivity with increasing structural (graphitic) order in the fibres. Overall, the electrical resistivity of cellulose-derived carbon fibres was between 40 and $70 \Omega \mu \mathrm{m}$, which exceeds the resistivity of fossil-based carbon fibre by a factor ten.
\end{abstract}

\section{Introduction}

Cellulosic fibres are an important resource for biobased materials. Above all, their renewability, biodegradability and favourable carbon balance are an undisputed advantage compared to fossil-based fibres [1, 2]. On the downside, the overall mechanical performance of cellulosic fibres is clearly inferior to fossil-based fibres, specifically widely used glass fibre, even when their comparably low density of max. $1.5 \mathrm{~g} \mathrm{~cm}^{-3}$ is considered [3-5]. Even so, there is a growing interest in using cellulosic fibres, not least because of increasing awareness for the importance of minimising the environmental footprint of materials $[2,6]$. Beyond applications in their native state, cellulosic fibres may, for example, also serve as renewable precursors for functional carbon fibre. It is well known that natural cellulose fibre served as the

Address correspondence to E-mail: wolfgang.gindl@boku.ac.at 
precursor for electric lamp filament, the first technical carbon fibre [7]. Cellulose-based carbon fibre for structural applications was developed around the middle of the past century, but due to economic limitations production ceased soon [8]. More recently, the interest in biogenic carbon fibre precursor has risen again, with strong focus on ligninbased precursors [9-11]. Compared to lignin, which is predominantly aromatic in structure, the polysaccharide cellulose is less suitable for the production of mechanically strong carbon structures [8, 12-14]. However, spinning of lignin into precursor fibres is challenging, whereas cellulose fibres are easily available in the shape of natural fibre from plants [15] or man-made cellulose fibre from well-established industrial processes [16, 17].

Natural cellulosic fibres are made up of individual elongated and thick-walled fibre cells or cell bundles. Individual fibre cells typically range from length of few millimetres, for example, in wood tissue [18] up to several centimetres in length in flax [19], with diameters of $10-20 \mu \mathrm{m}$. They mainly consist of partially crystalline cellulose (cellulose I) and varying amounts of non-cellulosic polysaccharides and lignin. The fibre extraction is carried out in classic wood pulping processes applied in the pulp and paper industry or, in the case of many annual fibre plants, by mechanical decortication, assisted by retting [20]. By contrast, man-made cellulose fibres are principally produced by spinning of dissolved chemical pulp into continuous filaments with typical diameter around $10 \mu \mathrm{m}$. At present, the most important industrial processes used are the viscose and the Lyocell process [16]. The advantage of man-made cellulose fibres over natural cellulose fibres lies in their much greater homogeneity and the option to tailor fibre properties according to the needs of users. Furthermore, they consist almost exclusively of cellulose (cellulose II) and can be produced as filaments of infinite length.

In the present study, two types of natural fibres and two types of man-made cellulose fibre are carbonised in order to study potential differences in the resulting structures. Furthermore, the electrical resistivity of the resulting carbon fibres will be evaluated in order to assess the suitability of cellulosebased carbon in applications requiring electrical conductivity, which is one of the major desired material features of carbon materials [21].

\section{Materials and methods}

\section{Carbonisation}

The materials used were hemp (Cannabis sativa), bleached ramie (Boehmeria nivea), commercial textile viscose and Tencel fibre (Fig. 1). Without any pretreatment, $20-100 \mathrm{mg}$ of fibre was carbonised in a GERO HTK8 oven with a volume of $6 \mathrm{~L}$. Argon atmosphere $\left(250 \mathrm{l} \mathrm{h}^{-1}\right)$ was used, and heating was performed at a rate of $5{ }^{\circ} \mathrm{C} \mathrm{min}{ }^{-1}$ up to $2000{ }^{\circ} \mathrm{C}$, which was held for $30 \mathrm{~min}$. During carbonisation, the specimens were free to shrink.

\section{Characterisation}

Thermogravimetry analysis (TGA) measurements were taken using a Netzsch TG 209 F1 Iris device. About $15 \mathrm{mg}$ of the fibres was wrapped into an aluminium foil and pressed tightly to the bottom of an aluminium oxide crucible in order to facilitate heat transfer. The sample was heated from ambient temperature to $600{ }^{\circ} \mathrm{C}$ at the rate of $10^{\circ} \mathrm{C} \mathrm{min}^{-1}$ in nitrogen atmosphere.

Microscopy was performed in a Quanta ${ }^{\mathrm{TM}} 250$ field emission scanning electron microscope (SEM) from FEI in high-vacuum secondary electron mode. For non-carbonised fibres, sputter coating with a thin gold layer was carried out prior to SEM.

Wide-angle X-ray scattering characterisation of cellulose and carbonised fibre bundles was performed using a laboratory instrument Nanostar (Bruker AXS) equipped with Incoatec Microfocus source providing $\mathrm{Cu}-\mathrm{K} \alpha$ radiation, two-dimensional Montel optics, two pinhole collimation system and a two-dimensional Image Plate detector. The collected diffraction data were processed using the software Fit2D [22]

Raman spectra were acquired using a Raman microscope (alpha300RA, WITec GmbH, Germany) equipped with a green laser $(\lambda=532 \mathrm{~nm})$, spectrometer with a $600 \mathrm{gm} \mathrm{m}^{-1}$ grating (UHTS 300 WITec, Germany) and a CCD camera (Andor DU401ABV, Belfast, North Ireland). The laser power was set to $5 \mathrm{~mW}$, and with an integration time of $0.08 \mathrm{~s}$, single spectra were collected from three specimens per fibre variant. Spectra were recorded at a step width of $0.5 \mu \mathrm{m}$ along a fibre section of $50-70 \mu \mathrm{m}$ length, resulting in approx. 3000 spectra for each 
Figure 1 Samples of cellulose fibres used for carbonisation experiments as received (a) and after carbonisation (b).
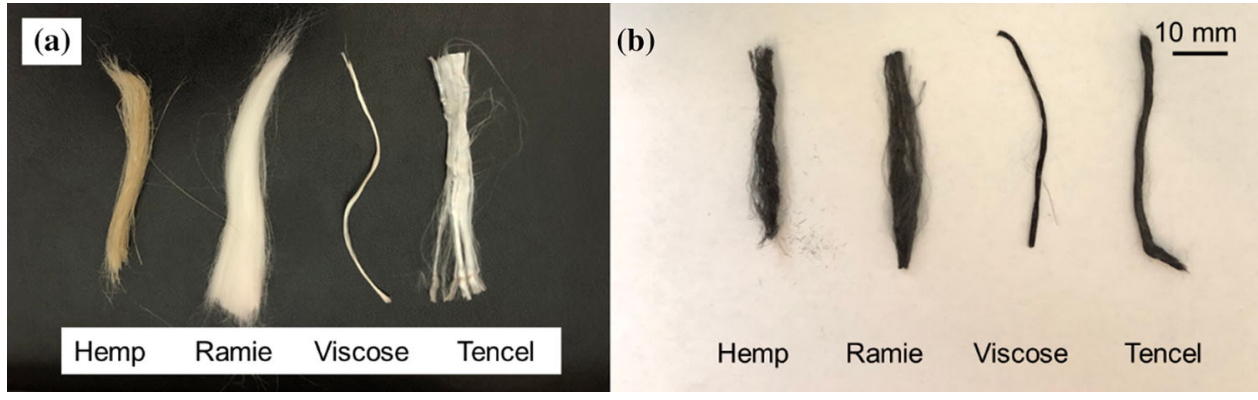

fibre. A $100 \times$ oil immersion objective (numerical aperture $(\mathrm{NA})=1.4$ ) was used. Finally, average spectra of all three fibres per variant were obtained for further analysis.

The electrical resistivity of single cellulose-based carbon fibres was measured with a hand-held multimeter. For this purpose, the ends of approx. 15-mmlong individual fibres were fixed to glass microscope slides by means of conductive silver paint (Silber Leitlack, Busch, Germany). The ohmic resistivity was measured by contacting the silver paint, and the free length and diameter of the fibres were measured using a Zeiss Axioplan Vis microscope equipped with camera and image analysis.

\section{Results and discussion}

The morphology of individual cellulose fibres before and after carbonisation is shown in Figs. 1 and 2. All fibre variants were received as fibre bundles with several centimetres length. With the exception of hemp, all fibres were of white colour. As revealed by SEM, the surface of natural fibres (Fig. 2a, b) is less smooth and uniform than the surface of man-made fibres (Fig. 2c, d). Besides these differences in morphology, the cellulosic ultra-structure of the cellulose fibres studied here differs significantly as demonstrated by results from wide-angle $X$-ray scattering (WAXS) (Fig. 3). Cellulose crystallites in all fibres possess a strong preferred orientation as indicated by narrow peaks in the azimuthal intensity distributions of the most intense cellulose 200 reflection. This is the case for both natural and man-made cellulose fibres, even though their crystalline fractions show different conformations, i.e. cellulose I in natural fibres vs cellulose II in man-made cellulose fibres. The differences in crystalline conformation entail different patterns in inter- and intramolecular hydrogen bonding, which are highly relevant, for example, for the mechanics of cellulose I and cellulose II [23]. However, according to the literature these differences in crystalline structure do not necessarily affect the graphitisation of cellulose fibres [24].

Since the full width at half maximum (FWHM) of the cellulose 200 peaks correlates with the degree of preferred orientation, FWHM may serve as a quantitative indicator. Preferred orientation increases from viscose (FWHM 20.8) to Tencel (FWHM 16.6) to hemp (14.8) to ramie (FWHM 12.6). Furthermore, also the degree of crystallinity is different in regenerated cellulose fibres compared to natural fibres. Viscose shows lowest crystallinity, typically $<30 \%$ [25], followed by Tencel with roughly $40 \%$ [25], and $>50 \%$ for natural fibres [26]. In the present study, radial $2 \Theta$ scans and the width and height of the cellulose 110 and 200 diffraction peaks confirm a similar trend (Fig. 3).

Upon carbonisation (Fig. 1b), all fibres turned uniformly black and were highly brittle as they easily broke down into small fragments due to handling. This was particularly pronounced for natural fibres, as shown in Fig. 1i, for example hemp. Carbonised natural fibres showed numerous cracks across their diameter, which facilitated fracture. By contrast, carbonised regenerated cellulose fibres (Fig. 1j) retained their structural integrity to a higher degree, with no cracks apparent in the SEM. No significant changes in surface appearance were discernible in the SEM after carbonisation (Fig. 2e-h). However, gravimetric analysis shows that roughly $90 \%$ of the initial mass of cellulose fibres was lost during carbonisation (Table 1). Among all four fibres, mass loss was most prominent for viscose. It is presumed that the comparably low crystallinity of viscose plays a role in the significant mass loss observed. In order to examine thermal degradation of the cellulose fibres in more detail, thermogravimetric analysis was carried out (Fig. 4). 
Figure 2 Scanning electron microscopy of single cellulose fibres a hemp, $\mathbf{b}$ ramie, c viscose, $\mathbf{d}$ Tencel and their carbonised counterparts $\mathbf{e}-$ h together with a lowmagnification image of carbonised natural hemp fibres (i) and Tencel regenerated cellulose fibres $(\mathbf{j})$.

Arrowheads in $\mathbf{i}$ indicate cracks across the diameter of carbonised fibres leading to easy fragmentation as shown in the inset (note that a pair of fibres is shown in $\mathbf{f}$ ).
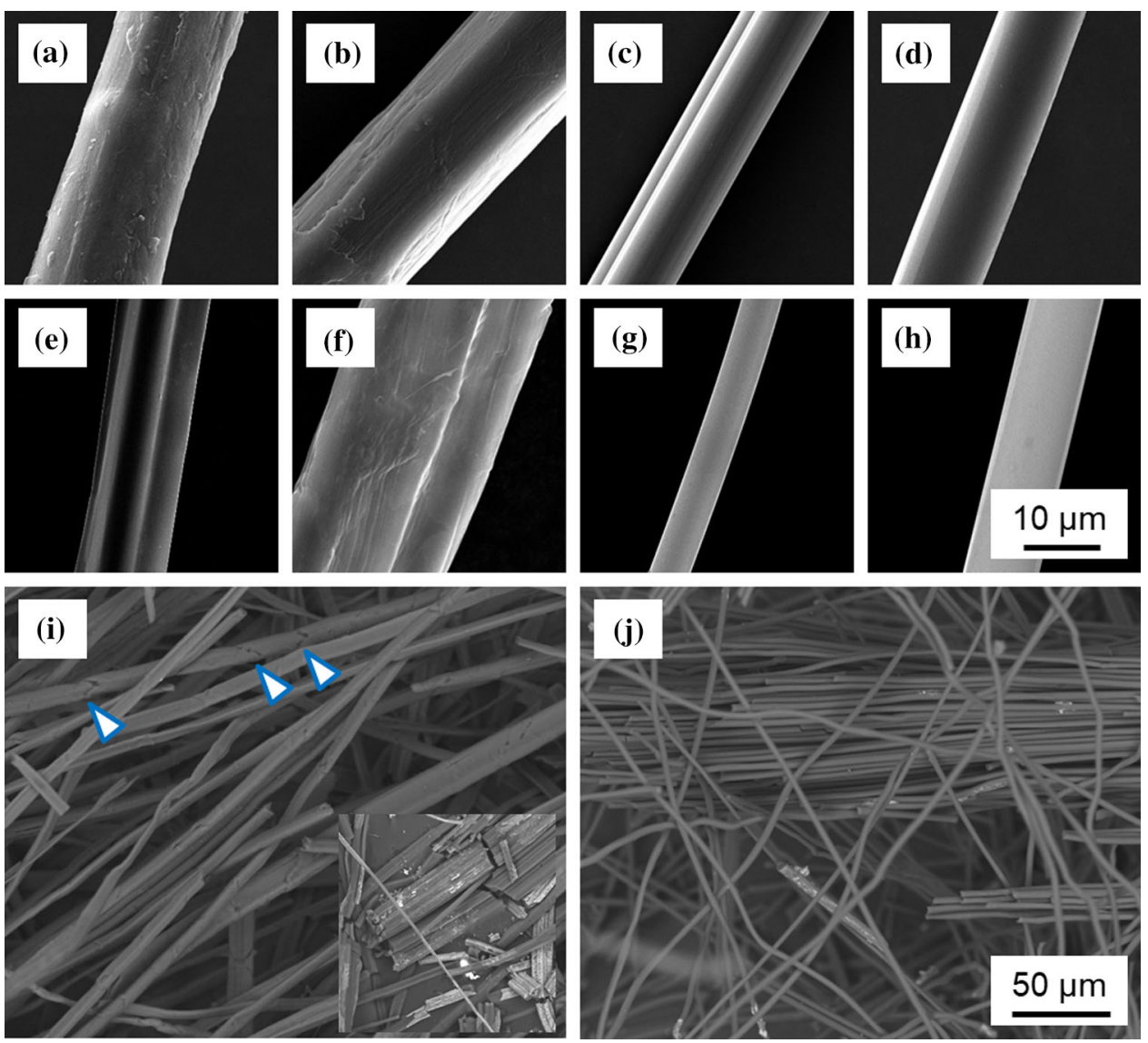

It is well known that cellulose exhibits very little thermal degradation up to temperatures of $280{ }^{\circ} \mathrm{C}$ [27]. The fibres characterised in the present study show similar thermal degradation characteristic with the exception of Tencel, where noticeable decomposition arises already at $231{ }^{\circ} \mathrm{C}$ (maximum slope). However, for all fibres the most intense thermal decomposition phase starts in the region between $240{ }^{\circ} \mathrm{C}$ and $280^{\circ} \mathrm{C}$ (onset). By comparison, the thermal stability indicated by the maximum slope of mass decay increases in the order viscose $\left(337^{\circ} \mathrm{C}\right)<$ hemp $\left(352{ }^{\circ} \mathrm{C}\right)<$ Tencel $\left(354{ }^{\circ} \mathrm{C}\right)<$ ramie $\left(366^{\circ} \mathrm{C}\right)$. In addition to a reduction in diameter indicated qualitatively in Fig. 2, a significant shrinkage in length also occurred, which was less pronounced for natural fibres than for man-made fibres (Table 1).

It is known that shrinkage in length during carbonisation is related to the degree of molecular orientation of cellulose in the precursor fibre [24]. Bacon and Tang [24] report a nonlinear relationship between the draw ratio applied to regenerated cellulose fibres during spinning and the shrinkage of these fibres during carbonisation. Up to a draw ratio of 1 , the rate of decrease in shrinkage with increasing draw ratio was constant, whereas it decreased at higher draw ratios. This kind of relationship agrees well with the observation that, using the example of regenerated cellulose fibres spun from a solution in ionic liquid [28], an increase in draw ratio from, for example, 1 to 1.5 entails a very significant improvement in orientation of crystalline cellulose in the fibre, whereas the additional improvement achieved by a further increase in draw ratio from 1.5 to 2 is much less significant. In the present study, orientation data of fibres are available from the quantitative evaluation of the azimuthal 200 peak width in terms of FWHM, which shows that there are clear differences in the degree of cellulose crystalline orientation of all four cellulose fibres used (Fig. 5).

When relating these orientation data to fibre shrinkage during carbonisation, a clear linear relationship is seen (Fig. 5). It is plausible that the extent of longitudinal shrinkage during carbonisation is governed by crystalline orientation in a similar fashion as is the case for positive and negative axial 
Figure 3 WAXS 2D detector images of cellulose fibre bundles with the azimuthal intensity distribution of the most intense cellulose 200 reflection shown in the upper insets and radial $2 \Theta$ scans shown in the lower insets: a hemp, $\mathbf{b}$ ramie, $\mathbf{c}$ viscose and d Tencel.
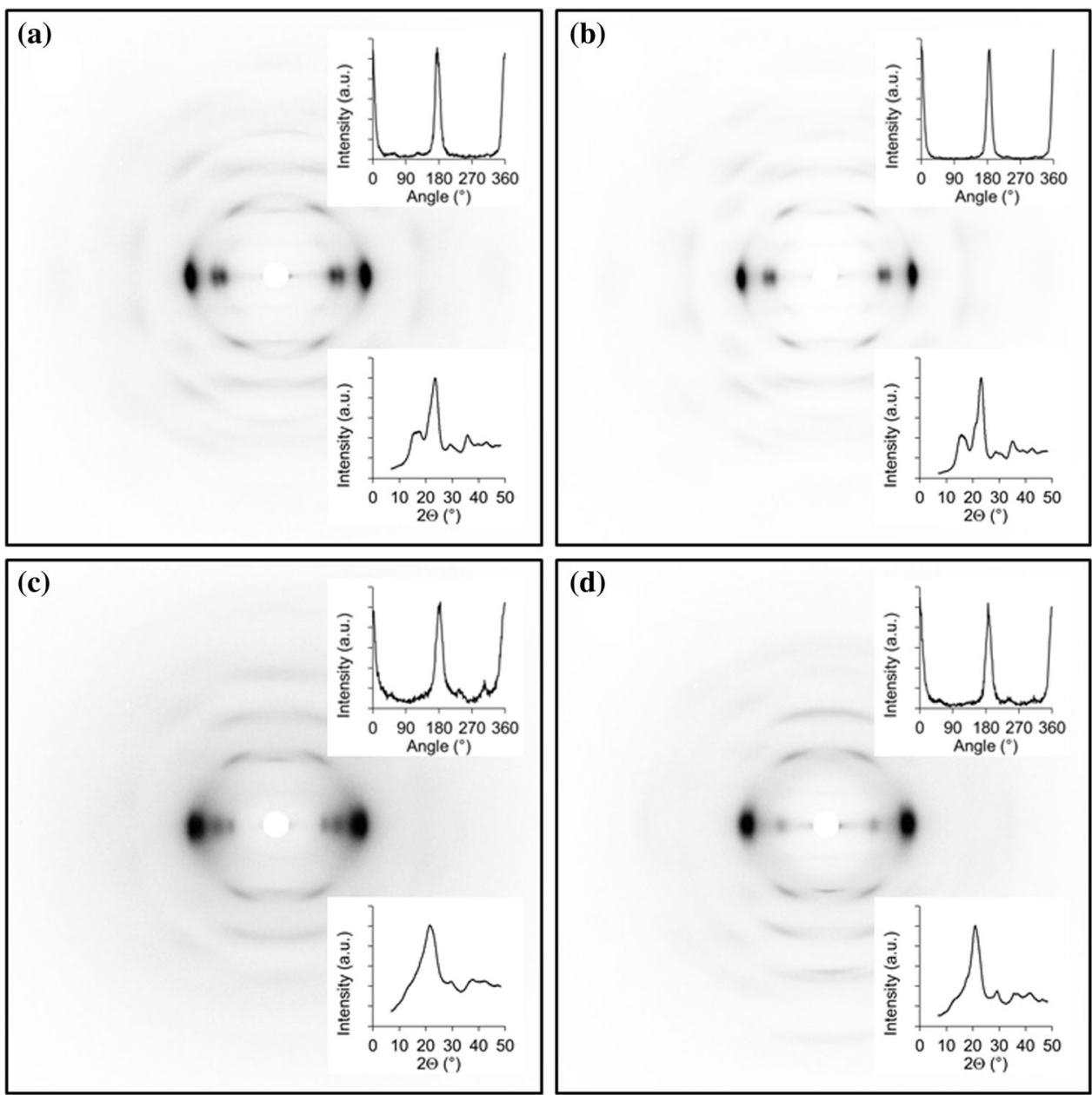

Table 1 Mass yield and length shrinkage observed during carbonisation of cellulose fibres (values determined for one fibre bundle of $20-100 \mathrm{mg}$ )

\begin{tabular}{lcl}
\hline Sample & Yield (\%) & Shrinkage (\%) \\
\hline Hemp & 13.2 & 30.0 \\
Ramie & 10.8 & 20.0 \\
Viscose & 6.3 & 48.9 \\
Tencel & 10.0 & 32.9 \\
\hline
\end{tabular}

strain in tensile [29] and bending [30] experiments. Upon both extension and contraction and irrespective of whether elastic or plastic deformation is considered, the relationship between strain and the degree of crystalline orientation in a cellulose fibre is always strictly linear $[29,30]$.

In addition to slight changes in morphology (Figs. 1, 2), mass loss and shrinkage (Table 1), carbonisation resulted in significant changes of fibre structure as revealed by WAXS and Raman spectroscopy. As shown in Fig. 6, only ramie- and Tencelderived fibres (Fig. 6b, d) show meaningful yet fairly moderate scattering intensities, whereas viscose and hemp (Fig. 6a, c) hardly show any scattering.

Ramie and Tencel exhibit diffraction patterns typical of graphite [31], with a clear peak at an angle around $26^{\circ}$ indicative of stacked graphene sheets. In contrast, carbon fibre derived from viscose and hemp appears to be composed of purely amorphous carbon. Based on mass loss data (Table 1) and low crystallinity, the poor structure of carbon fibre from viscose may be as expected, whereas the absence of graphitic structure in highly crystalline and welloriented hemp is somewhat surprising. Compared to bleached ramie and the two man-made cellulose fibres, hemp is probably more heterogeneous in chemistry as it typically contains 5-6\% hemicellulose and $11-12 \%$ lignin in addition to cellulose [32]. It is possible that this chemical heterogeneity, particularly 
Figure 4 Thermogravimetric analysis of different cellulose fibres.
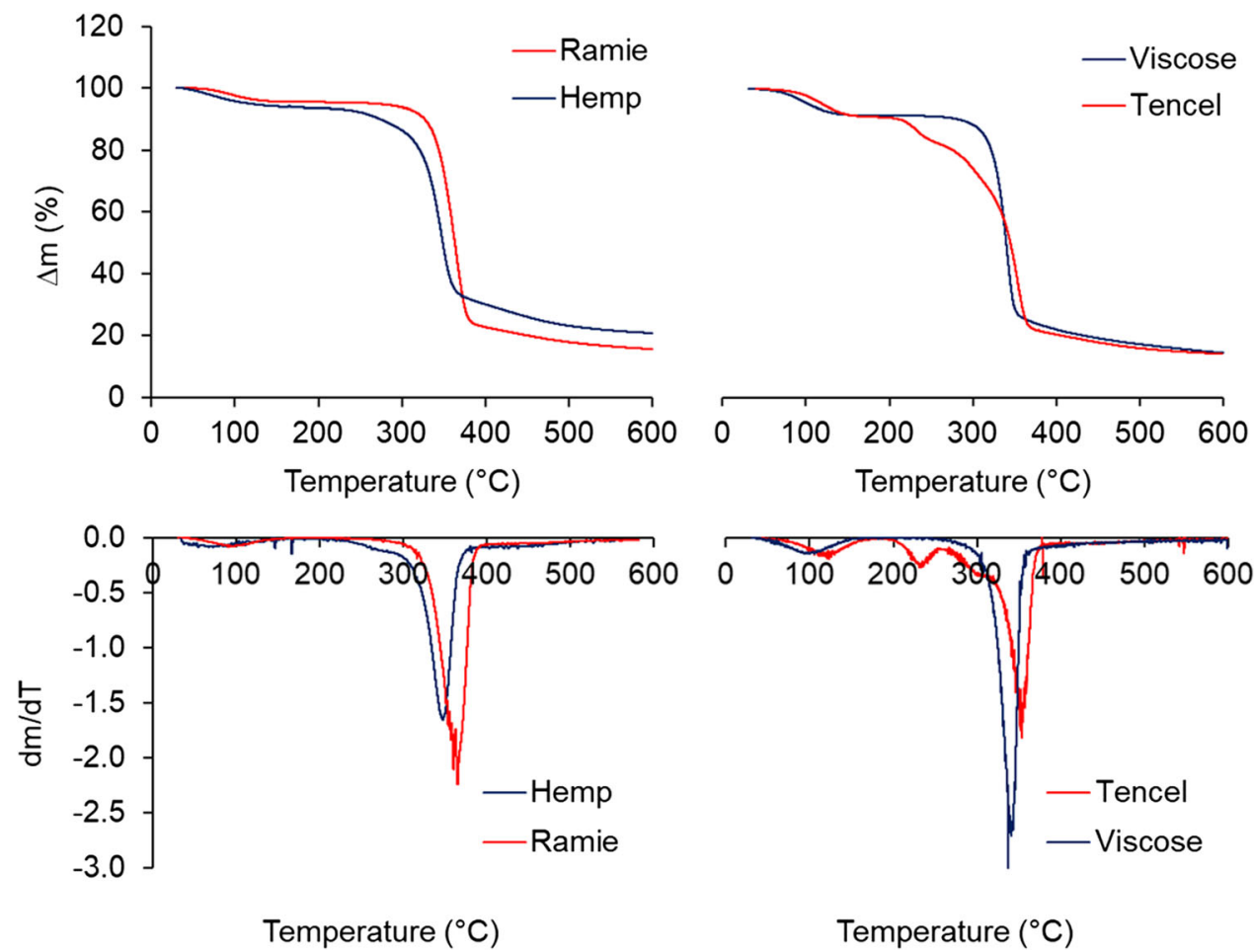

Temperature $\left({ }^{\circ} \mathrm{C}\right)$

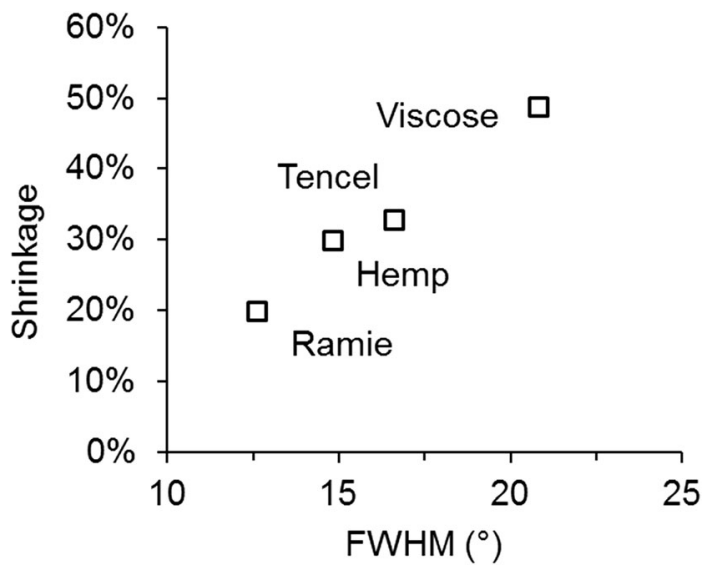

Figure 5 Correlation between longitudinal shrinkage of cellulose fibres during carbonisation and the degree of orientation of cellulose prior to carbonisation (decreasing FWHM indicates increasing preferred orientation).

acidic moieties originating from hemicellulose, may have negatively interfered with the formation of graphitic structure during the carbonisation process of hemp. Overall, the radial scattering intensity distribution from $2 \Theta$ scans of the $2 \mathrm{D}$ detector images shown in Fig. 6 is very similar to results from studies with comparable cellulosic fibres in the case of Tencel and ramie, showing distinct peaks at $26^{\circ}$ scattering angles [33, 34]. A highly intense and well-defined intensity peak at an angle around $26^{\circ}$ indicative of abundant stacked graphene sheets, which is observed in carbonised lignin structures [35, 36], is not seen in carbonised cellulose fibres. Interestingly, also a certain amount of preferred orientation is preserved in the carbonised variants of highly oriented Tencel and ramie, as seen in azimuthal intensity profiles (insets) shown in Fig. 6. Again, this agrees well with previous studies with similar material [34, 37].

WAXS results, which show higher structural order for ramie and Tencel compared to viscose and hemp, only partially agree with results from Raman spectroscopy. Raman spectra contain abundant information about the structure of carbon materials (Fig. 7).

The most prominent bands preferably analysed are the G-band at $\sim 1580 \mathrm{~cm}^{-1}$, which is associated with an ideal, highly ordered graphitic lattice, and the D-band at $1350 \mathrm{~cm}^{-1}$, which represents signal from a disordered graphitic lattice [38]. Consequently, the ratio between the peak intensities of the $D$ and $G$ peaks may serve as an indicator of structural order in carbon materials. Hence, structural order was more pronounced in the natural fibres hemp and ramie $\left(I_{D} /\right.$ $I_{G}=1.28$ and 1.17 , respectively) compared to the regenerated cellulose fibres Tencel and viscose $\left(I_{D} /\right.$ $I_{G}=1.45$ and 1.48 , respectively). These $I_{D} / I_{G}$ ratios are in a similar order of magnitude as found for 
Figure 6 Wide-angle X-ray scattering 2D detector images of carbonised cellulose fibre bundles with the azimuthal intensity distribution of the most intense graphite 200 reflection shown in the upper insets and radial $2 \Theta$ scans shown in the lower insets: a hemp, b ramie, $\mathbf{c}$ viscose and d Tencel.
Figure 7 Raman spectra of carbonised cellulose fibre bundles.
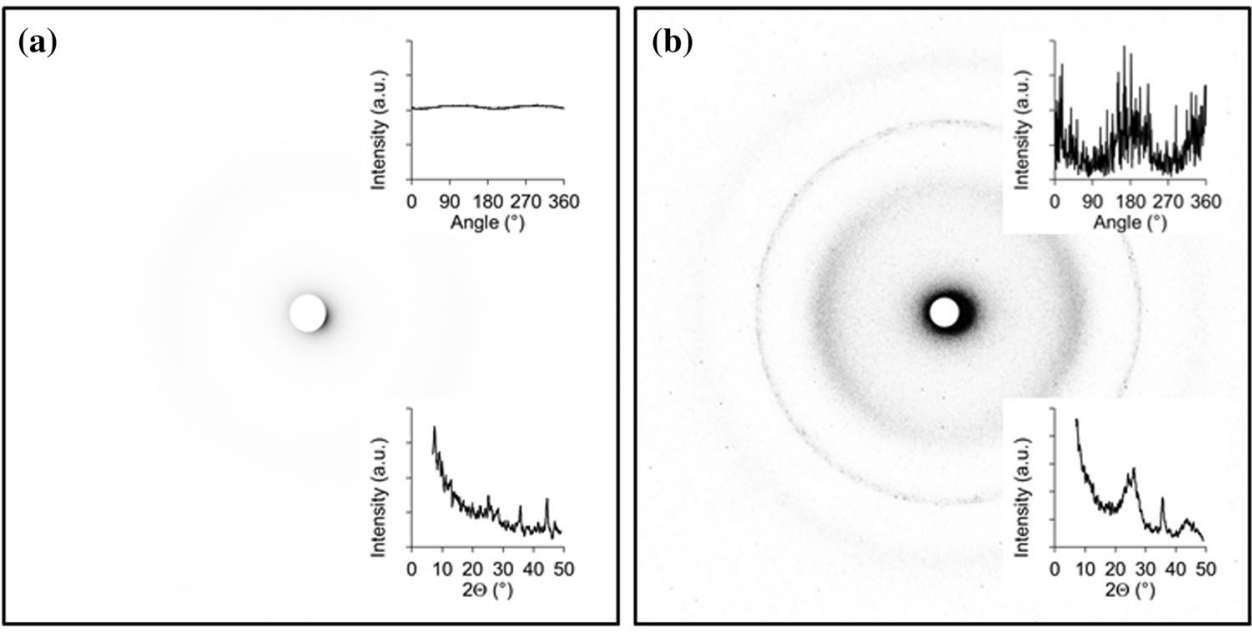

(c)
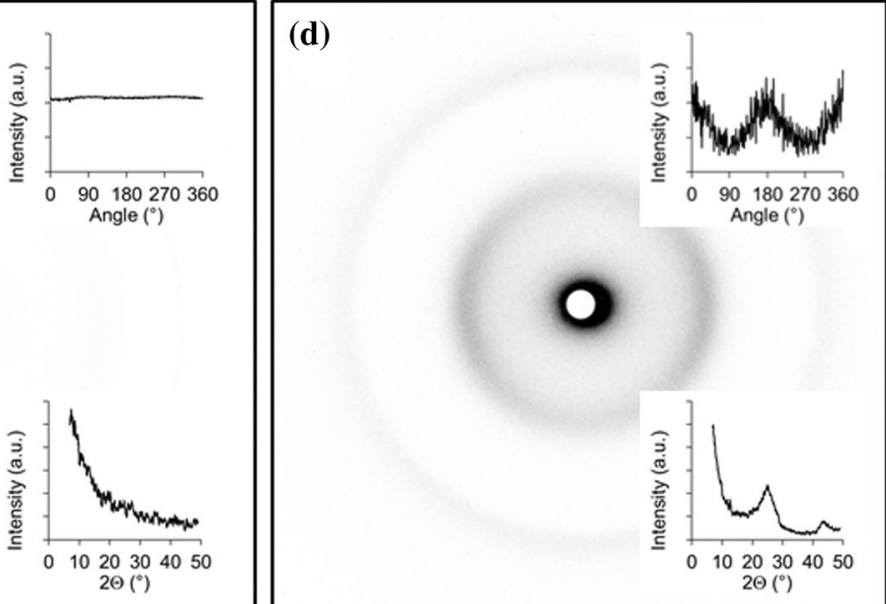
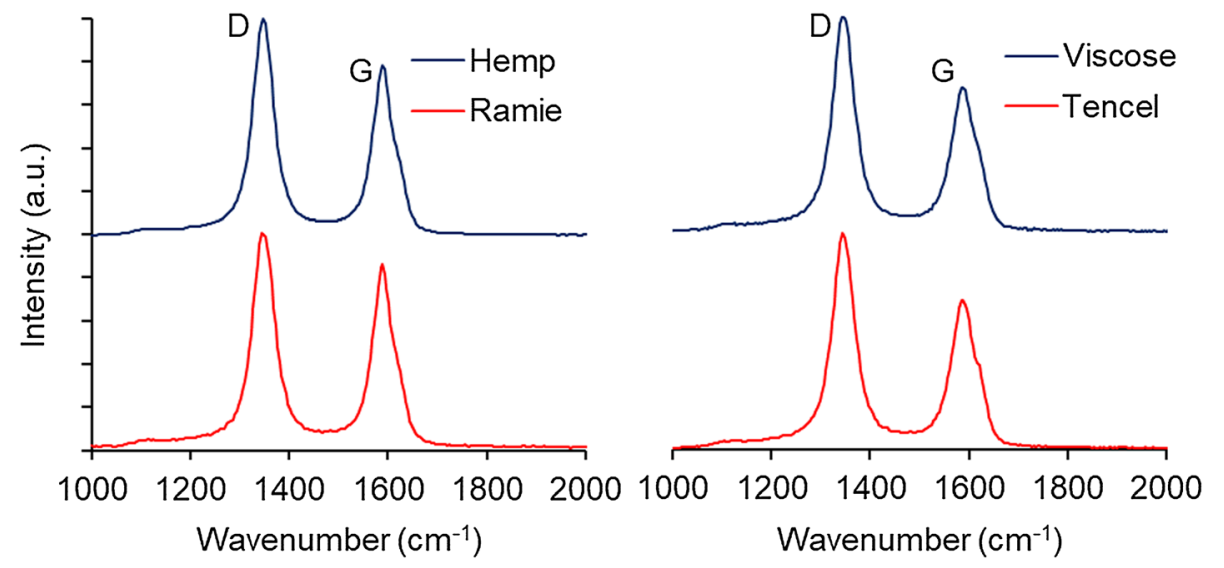

mesoporous carbon obtained from lignin nanofibre networks [39], but significantly higher than $I_{D} / I_{G}$ of 0.25 and 0.60 obtained for electrically conducting carbon produced by direct carbonisation of kraft and sulphite pulping liquors, respectively [35]. In an analysis of carbon fibre produced from ultra-highperformance regenerated cellulose fibre, a progressive increase in $I_{D} / I_{G}$ from 0.7 to 1.4 with treatment temperature increasing from 400 to $1500{ }^{\circ} \mathrm{C}$ was reported [34]. Similar trends were also reported for Rayon tirecord-type regenerated cellulose fibre [37].

Good mechanical performance is one main parameter of interest when studying cellulose-based 
carbon fibre. However, in the absence of stretching during carbonisation, which is required for achieving good orientation and ensuing strength [17], the mechanics of carbon fibres produced in the present study were very poor. Therefore, we focus on electrical resistivity as a potential feature of interest for application. As shown in Fig. 8, the average electrical resistivity of most cellulose-derived carbon fibres is in the order of $45 \Omega \mu \mathrm{m}-55 \Omega \mu \mathrm{m}$. Carbonised hemp is an exception as it shows very high average resistivity of $135 \Omega \mu \mathrm{m}$ and high variability. It is presumed that cracks across the fibres which were observed in abundance for carbonised hemp (Fig. 2i) significantly diminish the local conductive cross section of a carbon fibre, resulting in significantly increased overall resistivity. Disregarding hemp due to this anomaly, the trend of resistivity is ramie $<$ Tencel $<$ viscose, although not at a level of statistical significance. Even so, there is agreement between this trend in resistivity and the peak area of the graphite peak at $2 \Theta=26^{\circ}$ shown in Fig. 6 . While viscose-derived carbon fibre, which shows highest resistivity, exhibits no such peak, ramie-derived carbon, with lowest resistivity, shows the highest peak area, the peak area of Tencel-derived amounting to $75 \%$ of that of ramie. In a similar fashion, also the $I_{D} /$ $I_{G}$ ratio derived from Raman spectra (Fig. 7) replicates this trend. Here, the sequence is ramie $(1.17)<$ Tencel $(1.45)<$ viscose (1.48). In summary, without statistical significance, there is a trend for the electrical resistivity of cellulose-derived carbon fibre to decrease with an increase in the content of graphitic carbon as indicated by WAXS (Fig. 6) and an increase in the proportion of highly ordered graphitic lattice as indicated by Raman spectroscopy (Fig. 7).

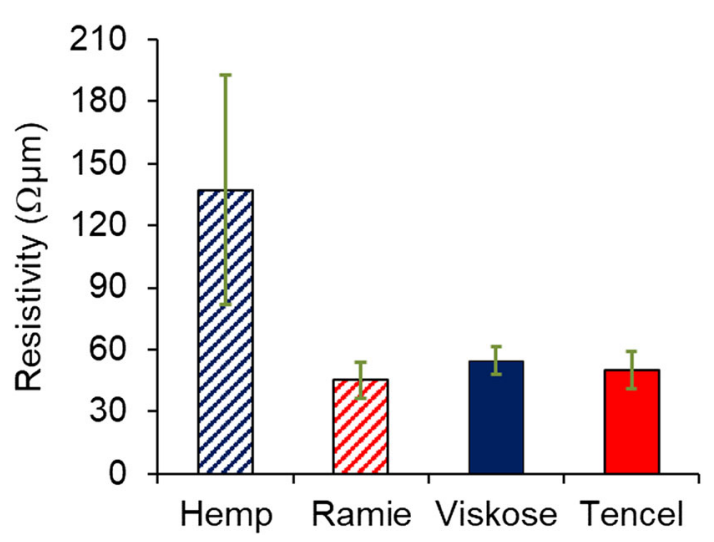

Figure 8 Electrical resistivity of single cellulose-derived carbon fibres.
This is also in good agreement with WAXS and Raman data obtained from lignin-derived carbon [35].

By comparison with cellulose-derived carbon, the electrical resistivity of conventional PAN-based carbon fibre is $7-14 \Omega \mu \mathrm{m}$, and pitch-based carbon ranges between 1.5 and $13 \Omega \mu \mathrm{m}$ [40]. Thus, cellulosederived carbon fibre shows electrical resistivity increased by a factor 10 compared to fossil-derived carbon. However, compared to lignin-derived carbon (10.000-100.000 $\Omega \mu \mathrm{m}$ [35]) and industrial carbon black (4.000-25.000 $\Omega \mu \mathrm{m}$ [41]) used as filler for conductive polymers, very favourable low resistivity is given in the cellulose-derived carbon fibres studied here.

\section{Conclusions}

The electrical resistivity of individual carbon fibres produced by high-temperature carbonisation of natural and man-made cellulose fibres ranges between 50 and $140 \Omega \mu \mathrm{m}$. Apart from the fact that microcracks may contribute to high resistivity in carbonised natural fibres, no clear correlations between the structures of cellulose fibres and carbon fibres produced thereof were found. It is concluded that in terms of electrical resistivity achieved, the most important structural variable may be the fact that all fibres were high-orientation cellulose fibres providing carbon fibre with similar resistivity, and that differences in crystallinity, cellulose crystal type, etc. are only of secondary importance in the carbonisation process.

\section{Acknowledgements}

Open access funding provided by University of Natural Resources and Life Sciences Vienna (BOKU).

\section{Funding}

This study was financed in part by the European Regional Development Fund (EFRE) and the province of Upper Austria through the programme IWB 2014-2020 (Project BioCarb-K). 


\section{Compliance with ethical standards}

Conflict of interest The authors declare that they have no conflict of interest.

Open Access This article is licensed under a Creative Commons Attribution 4.0 International License, which permits use, sharing, adaptation, distribution and reproduction in any medium or format, as long as you give appropriate credit to the original author(s) and the source, provide a link to the Creative Commons licence, and indicate if changes were made. The images or other third party material in this article are included in the article's Creative Commons licence, unless indicated otherwise in a credit line to the material. If material is not included in the article's Creative Commons licence and your intended use is not permitted by statutory regulation or exceeds the permitted use, you will need to obtain permission directly from the copyright holder. To view a copy of this licence, visit http://creativecommons.org/licen ses/by $/ 4.0 /$.

\section{References}

[1] Shen L, Worrell E, Patel MK (2012) Comparing life cycle energy and GHG emissions of bio-based PET, recycled PET, PLA, and man-made cellulosics. Biofuels Bioprod Biorefining 6:625-639

[2] Dicker MPM, Duckworth PF, Baker AB, Francois G, Hazzard MK, Weaver PM (2014) Green composites: a review of material attributes and complementary applications. Compos Part A Appl Sci Manuf 56:280-289

[3] Adusumali RB, Reifferscheid M, Weber H, Roeder T, Sixta H, Gindl W (2006) Mechanical properties of regenerated cellulose fibres for composites. Macromol Symp 244:119-125

[4] Shah DU (2013) Developing plant fibre composites for structural applications by optimising composite parameters: a critical review. J Mater Sci 48:6083-6107. https://doi.org/ 10.1007/s10853-013-7458-7

[5] Bourmaud A, Beaugrand J, Shah DU, Placet V, Baley C (2018) Towards the design of high-performance plant fibre composites. Prog Mater Sci 97:347-408

[6] Correa JP, Montalvo-Navarrete JM, Hidalgo-Salazar MA (2019) Carbon footprint considerations for biocomposite materials for sustainable products: a review. J Clean Prod 208:785-794

[7] Edison TA (1892) Manufacture of filaments for incandescent electric lamps USA Patent 470925,
[8] Dumanlı AG, Windle AH (2012) Carbon fibres from cellulosic precursors: a review. J Mater Sci 47:4236-4250. http s://doi.org/10.1007/s10853-011-6081-8

[9] Kadla JF, Kubo S, Venditti RA, Gilbert RD, Compere AL, Griffith W (2002) Lignin-based carbon fibers for composite fiber applications. Carbon 40:2913-2920

[10] Baker DA, Rials TG (2013) Recent advances in low-cost carbon fiber manufacture from lignin. J Appl Polym Sci 130:713-728

[11] Meek N, Penumadu D, Hosseinaei O, Harper D, Young S, Rials T (2016) Synthesis and characterization of lignin carbon fiber and composites. Compos Sci Technol 137:60-68

[12] Ogale AA, Zhang M, Jin J (2016) Recent advances in carbon fibers derived from biobased precursors. J Appl Polym Sci 133:43794

[13] Bengtsson A, Bengtsson J, Olsson C, Sedin M, Jedvert K, Theliander H, Sjoholm E (2018) Improved yield of carbon fibres from cellulose and kraft lignin. Holzforschung 72:1007-1016

[14] Bengtsson A, Bengtsson J, Sedin M, Sjöholm E (2019) Carbon fibers from lignin-cellulose precursors: effect of stabilization conditions. ACS Sustain Chem Eng 7:8440-8448

[15] Bledzki AK, Gassan J (1999) Composites reinforced with cellulose based fibres. Prog Polym Sci 24:221-274

[16] Woodings C (2001) Regenerated cellulose fibres. Woodhead publishing, Cambridge

[17] Byrne N, Setty M, Blight S, Tadros R, Ma YB, Sixta H, Hummel M (2016) Cellulose-derived carbon fibers produced via a continuous carbonization process: investigating precursor choice and carbonization conditions. Macromol Chem Phys 217:2517-2524

[18] Salminen LI, Liukkonen S, Alava MJ (2014) Ground wood fiber length distributions. BioResources 9:1168-1178

[19] Goudenhooft C, Bourmaud A, Baley C (2019) Flax (Linum usitatissimum L.) fibers for composite reinforcement: exploring the link between plant growth, cell walls development, and fiber properties. Front Plant Sci 10:411-411

[20] Tahir PM, Ahmed AB, SaifulAzry SOA, Ahmed Z (2011) Retting process of some bast plant fibres and its effect on fibre quality: a review. BioResources 6:5260-5281

[21] Chung DDL (2004) Electrical applications of carbon materials. J Mater Sci 39:2645-2661. https://doi.org/10.1023/B: JMSC.0000021439.18202.ea

[22] Hammersley AP (1997) FIT2D: An introduction and overview. ESRF Internal Report ESRF97HA02T

[23] Northolt MG, den Decker P, Picken SJ, Baltussen JJM, Schlatmann R (2005) The tensile strength of polymer fibres. Adv Polym Sci 178:1-108 
[24] Bacon R, Tang MM (1964) Carbonization of cellulose fibers-II Physical property study. Carbon 2:221-225

[25] Fink HP, Weigel P, Purz HJ, Ganster J (2001) Structure formation of regenerated cellulose materials from NMMOsolutions. Prog Polym Sci 26:1473-1524

[26] Park S, Baker JO, Himmel ME, Parilla PA, Johnson DK (2010) Cellulose crystallinity index: measurement techniques and their impact on interpreting cellulase performance. Biotechnol Biofuels 3:10

[27] Di Blasi C (2008) Modeling chemical and physical processes of wood and biomass pyrolysis. Prog Energy Combust Sci $34: 47-90$

[28] Wanasekara ND, Michud A, Zhu C, Rahatekar S, Sixta H, Eichhorn SJ (2016) Deformation mechanisms in ionic liquid spun cellulose fibers. Polymer 99:222-230

[29] Gindl W, Reifferscheid M, Martinschitz KJ, Boesecke P (2008) Keckes, J (2008): Reorientation of crystalline and noncrystalline regions in regenerated cellulose fibers and films tested in uniaxial tension. J Polym Sci B-Polym Phys 46(3):297-304

[30] Gindl W, Martinschitz KJ, Boesecke P, Keckes J (2006) Orientation of cellulose crystallites in regenerated cellulose fibres under tensile and bending loads. Cellulose 13:621-627

[31] Li ZQ, Lu CJ, Xia ZP, Zhou Y, Luo Z (2007) X-ray diffraction patterns of graphite and turbostratic carbon. Carbon 45:1686-1695

[32] Jankauskienė Z, Butkutė B, Gruzdevienė E, Cesevičienė J, Fernando AL (2015) Chemical composition and physical properties of dew- and water-retted hemp fibers. Ind Crops Prod 75:206-211

[33] Kong K, Deng L, Kinloch IA, Young RJ, Eichhorn SJ (2012) Production of carbon fibres from a pyrolysed and graphitised liquid crystalline cellulose fibre precursor. J Mater Sci 47:5402-5410. https://doi.org/10.1007/s10853-012-6426-y
[34] Kim D-Y, Nishiyama Y, Wada M, Kuga S (2001) Graphitization of highly crystalline cellulose. Carbon 39:1051-1056

[35] Köhnke J, Rennhofer H, Lichtenegger H, Ar M, Unterweger C, Prats-Mateu B, Gierlinger N, Schwaiger E, Mahler A-K, Potthast A, Gindl-Altmutter W (2018) Electrically conducting carbon microparticles by direct carbonization of spent wood pulping liquor. ACS Sustain Chem Eng 6:3385-3391

[36] Gindl-Altmutter W, Köhnke J, Unterweger C, Gierlinger N, Keckes J, Zalesak J, Rojas OJ (2019) Lignin-based multiwall carbon nanotubes. Compos Part A Appl Sci Manuf 121:175-179

[37] Lewandowska AE, Soutis C, Savage L, Eichhorn SJ (2015) Carbon fibres with ordered graphitic-like aggregate structures from a regenerated cellulose fibre precursor. Compos Sci Technol 116:50-57

[38] Sadezky A, Muckenhuber H, Grothe H, Niessner R, Pöschl U (2005) Raman microspectroscopy of soot and related carbonaceous materials: Spectral analysis and structural information. Carbon 43:1731-1742

[39] Ago M, Borghei M, Haataja JS, Rojas OJ (2016) Mesoporous carbon soft-templated from lignin nanofiber networks: microphase separation boosts supercapacitance in conductive electrodes. RSC Adv 6:85802-85810

[40] Emmerich FG (2014) Young's modulus, thermal conductivity, electrical resistivity and coefficient of thermal expansion of mesophase pitch-based carbon fibers. Carbon 79:274-293

[41] Sánchez-González J, Macías-García A, Alexandre-Franco MF, Gómez-Serrano V (2005) Electrical conductivity of carbon blacks under compression. Carbon 43:741-747

Publisher's Note Springer Nature remains neutral with regard to jurisdictional claims in published maps and institutional affiliations. 